\title{
Monitoring Menggunaan Daya Listrik Sebagai Implementasi Internet of Things Berbasis Wireless Sensor Network
}

\author{
I Gusti Putu Mastawan Eka Putra ${ }^{1}$, Ida Ayu Dwi Giriantari ${ }^{2}$, Lie Jasa ${ }^{3}$
}

\begin{abstract}
One implementation of the Internet of Things (IoT) conducted in this study to realize the system of monitoring and control of electrical energy usage-based Wireless Sensor Network (WSN). This research method is the design of wireless sensor nodes that can measure the electrical parameters of alternating current $(A C)$ as effective voltage, effective current, active power, apparent power, power factor and total electrical energy consumption by using modules ESP8266 as a liaison with a Wi-Fi. Calculation of electrical parameters obtained from ATmega328P microcontroller $A D C$ readings of a step-down transformer that is used as a voltage sensor and sensor SCTO13 used as AC current sensors will be transmitted to the server over the network from a Wi-Fi Access Point (AP). ESP8266 modules are programmed using AT-Command proven to reliably measure can transmit data simultaneously with serial data format of the wireless sensor node to a server using TCP / $I P$ protocol. Monitoring power consumption via the internet which are designed in the research, either through the Android application and web browser proven to be reliably able to show some electrical parameters with the same data than the data logger recaps taken from SD-Card installed in the wireless sensor node.
\end{abstract}

Intisari - Salah satu implementasi Internet of Things (IoT) yang dilakukan pada penelitian ini untuk mewujudkan sistem monitoring dan kontrol penggunaan energi listrik berbasis Wireless Sensor Network (WSN). Metode penelitian ini adalah rancang bangun wireless node sensor yang bisa mengukur parameter listrik arus bolak-balik (AC) seperti tegangan efektif, arus efektif, daya aktif, daya semu, faktor daya dan jumlah pemakaian energi listrik dengan menggunakan modul ESP8266 sebagai penghubung dengan jaringan Wi-Fi. Perhitungan parameter-parameter listrik yang diperoleh dari pembacaan ADC mikrokontroler ATmega328P dari transformator step down yang digunakan sebagai sensor tegangan dan sensor SCT013 yang digunakan sebagai sensor arus listrik AC akan ditransmisikan ke server melalui jaringan Wi-Fi dari suatu Access Point (AP). Modul ESP8266 yang diprogram menggunakan $A T$ Command terbukti secara handal dapat mengirimkan data ukur secara bersamaan dengan format data serial dari wireless node sensor ke suatu server menggunakan protocol TCP/IP. Monitoring penggunaan daya listrik melalui internet yang dirancang pada penelitian, baik melalui aplikasi Android maupun web browser terbukti secara handal mampu menampilkan beberapa parameter listrik dengan data yang sama dibandingkan dengan rekapan data logger yang diambil dari SD-Card yang terpasang pada wireless node sensor.

Kata kunci: Internet of Things, Wireless Sensor Network, Modul ESP8266, AT-Command

\footnotetext{
${ }^{1}$ Mahasiswa Pascasarjana, Jurusan Teknik Elektro dan Komputer Fakultas Teknik Universitas Udayana, Jl. Kampus Bukit Jimbaran (telp:082280001978; e-mail: mastawan@pnb.ac.id)

${ }^{2,3}$ Dosen, Jurusan Teknik Elektro dan Komputer Fakultas Teknik Universitas Udayana, Jl. Kampus Bukit Jimbaran 80361 (telp/fax: 0361-703315; e-mail: dayu.giriantari@unud.ac.id, lieiasa@unud.ac.id)
}

\section{PENDAHULUAN}

Penghematan dalam penggunaan energi listrik merupakan langkah awal yang dapat dilakukan untuk membantu pemerintah dalam mengurangi defisit sumber ketenagalistrikan di Indonesia. Dalam pemanfaatannya terkadang tidak diketahui berapa banyak energi yang sudah terpakai sehingga cenderung terjadi pemborosan energi lisrik, sehingga perlu dilakukan pengukuran penggunaan energi listrik tersebut.[1] Perkembangan teknologi internet saat ini bukan saja hanya menghubungkan orang, namun menghubungkan orang dengan benda, dan juga benda dengan benda. Hal ini dikenal dengan Internet of Things (IoT) yang dapat dipahami sebagai lapisan informasi digital yang mencakup dunia fisik yang memungkinkan berbagai perangkat untuk saling berkomunikasi satu sama lain.[2] Wireless Sensor Network (WSN) merupakan salah satu bagian implementasi dari IoT yang terdiri dari kumpulan node sensor yang tersebar di suatu area tertentu. Tiap node sensor memiliki kemampuan untuk mengumpulkan data dan berkomunikasi dengan node sensor lainnya melalui komunikasi nirkabel. Dengan adanya komponen radio dalam WSN bisa memudahkan dalam proses untuk pengkabelan dari sistem yang dibangun, selain itu adanya processor dan sensor yang terintegrasi dalam WSN berpotensi menjadikan suatu monitoring dan kontrol menjadi smart system.[3]

Dari perkembangan teknologi Internet of Things yang sudah mulai memasyarakat saat ini, muncul pemikiran untuk mengintegrasikan beberapa sistem sensor tegangan dan arus listrik bolak-balik (AC) yang terhubung secara nirkabel melalui suatu jaringan $\mathrm{Wi}-\mathrm{Fi}$ untuk memonitor penggunaan energi listrik secara on-line melalui internet web browser maupun aplikasi Android. Metode penelitian yang digunakan adalah rancang bangun wireless node sensor dengan menggunakan modul ESP8266 sebagai penghubung dengan server melalui jaringan $\mathrm{Wi}-\mathrm{Fi}$ yang tersedia.

\section{TINJAUAN PUSTAKA}

\section{A. Wireless Sensor Network}

Dalam perkembangannya, bukan hanya manusia yang butuh terkoneksi dengan jaringan komputer, namun juga perangkat fisik seperti sensor butuh untuk terhubung dalam jaringan untuk melakukan telemonitoring parameter fisik pada lingkungan sampai dengan proses pengendalian. Wireless Sensor Network (WSN) terdiri dari node individu yang mampu berinteraksi dengan lingkungan mereka dengan merasakan atau mengendalikan parameter fisik. Node ini harus bekerja sama untuk memenuhi tugas-tugas mereka, dan 
mereka menggunakan komunikasi nirkabel untuk memungkinkan kolaborasi ini. Setiap node mengandung beberapa fungsi seperti perhitungan, komunikasi nirkabel, dan penginderaan atau fungsi kontrol.[4] Sensor menjadi bersifat mobile, artinya pada suatu saat dimungkinkan untuk memindahkan sensor untuk mendapat pengukuran yang lebih tepat tanpa harus khawatir mengubah disain ruangan maupun susunan kabel ruangan.

WSN terbagi atas lima bagian, yaitu transceiver (transmitter-receiver), mikrokontroler, power supply, memori eksternal, dan sensor. Transceiver berfungsi untuk menerima atau mengirim data dengan menggunakan protokol IEEE 802.15.4 atau IEEE 802.11b/g kepada device lain seperti concentrator, modem Wifi, atau modem RF. Mikrokontroler berfungsi untuk melakukan fungsi perhitungan, mengontrol dan memproses device-device yang terhubung. Power supply berfungsi sebagai sumber energi bagi sistem wireless sensor secara keseluruhan. Memori eksternal berfungsi sebagai tambahan memori bagi sistem wireless sensor. Sensor berfungsi untuk men-sensing besaran-besaran fisik yang hendak diukur dan mengubah besaran yang diukur menjadi energi listrik yang kemudian diolah oleh ADC (analog to digital converter) menjadi deretan pulsa terkuantisasi yang bisa dibaca dan diproses oleh mikrokontroler.[5]

\section{B. Internet of Things (IoT)}

Ide awal Internet of Things pertama kali dimunculkan oleh Kevin Ashton pada tahun 1999 dimana benda-benda di sekitar kita dapat berkomunikasi antara satu sama lain melalui sebuah jaringan seperti internet. Berawal dari Auto-ID Center, teknologi yang berbasis pada Radio Frequency Identification(RFID) yang merupakan identifikasi kode produk elektronik yang bersifat unik ini kemudian berkembang menjadi teknologi bahwa pada setiap benda dapat memiliki alamat Internet Protocol(IP). Dengan semakin berkembangnya infrastruktur internet, maka kita menuju babak berikutnya, di mana bukan hanya smartphone atau komputer saja yang dapat terkoneksi dengan internet. Namun berbagai macam benda nyata akan terkoneksi dengan internet.[6] Saat ini milyaran orang saling terhubung melalui jaringan internet, mereka saling bertukar pengetahuan, hiburan, dan lain-lain melintasi kota dan negara bahkan benua. Internet telah menghubungkan orang di seluruh dunia. Internet adalah seluruh jaringan komputer yang saling terhubung menggunakan standar sistem global Transmission Control Protocol/Internet Protocol (TCP/IP) sebagai protokol pertukaran paket (packet switching communication protocol) untuk melayani milyaran pengguna di seluruh dunia.

Perkembangan sekarang mengantarkan teknologi jaringan yang bukan saja hanya menghubungkan orang, namun menghubungkan orang dengan benda, dan juga benda dengan benda. Inilah dimulainya era Internet of Things (IoT) yang dapat dipahami sebagai lapisan informasi digital yang mencakup dunia fisik. Arsitektur IoT terdiri dari berbeda teknologi pendukung IoT. Ini berfungsi untuk menggambarkan bagaimana berbagai teknologi berhubungan satu sama lain dan saling berkomunikasi dengan skalabilitas, modularitas dan konfigurasi penyebaran IoT dalam skenario yang berbeda.[7]

\section{Modul ESP8266}

Modul ESP8266 adalah Wi-Fi modul dengan output serial TTL yang dilengkapi dengan GPIO, modul ini dapat dipergunakan secara standalone maupun dengan mikrokontroler tambahan untuk kendalinya. Modul ini merupakan modul low-cost Wi-Fi dengan dukungan penuh untuk penggunaan TCP/IP. Modul ini diproduksi oleh Espressif Chinese manufacturer. Pada tahun 2014, AI-Thinker manufaktur pihak ketiga dari modul ini mengeluarkan modul ESP-01, modul ini menggunakan AT-Command untuk konfigurasinya.[8] Pada rancangan sistem monitoring penggunaan daya listrik ini, modul ESP8266 digunakan untuk mengirimkan beberapa parameter listrik AC yang diproses oleh mikrokontroler ATmega328P ke suatu jaringan Wi-Fi dari suatu Access Point (AP) yang sudah tersedia. Sebelum proses komunikasi terjadi, terlebih dahulu modul ini akan melakukan inisialisasi terlebih dahulu untuk selanjutnya memperoleh IP Address dari AP yang digunakan. IP address yang digunakan adalah private IP kelas $\mathrm{C}$ dengan network ID 192.168.0.0 Subnet Mask 255.255.255.0.

\section{Sensor Arus Listrik AC SCT013}

Teknologi sensor arus hampir sama dengan teknologi sensor tegangan yaitu dengan menggunakan trafo arus yang dikenal dengan Current Trafo (CT) dan dengan menggunakan teknologi efek hall. Sensor ini tergolong komponen yang memiliki tingkat stabilitas yang baik. Jenis sensor arus yang banyak dipakai adalah The Yhdc current transformer dikenal sebagai CT sensor, sebuah non-invansive sensor yang dapat mendeteksi aliran arus yang melalui sebuah kawat penghantar. Dalam proses induksi, arus listrik yang melalui kawat sisi primer akan menghasilkan sebuah medan magnet pada inti ferrite CT sensor. Sensor SCT013 ditunjukkan seperti pada Gambar 1. Kawat pada sisi sekunder yang mengelilingi inti tersebut menghasilkan arus listrik kecil yang proporsional. Selanjutnya CT sensor dengan penambahan sebuah resistor kecil (Burden Resistor) akan menghasilkan keluaran berupa tegangan yang dapat diolah oleh mikrokontroler melalui masukan analog to digital converter (ADC).[9]

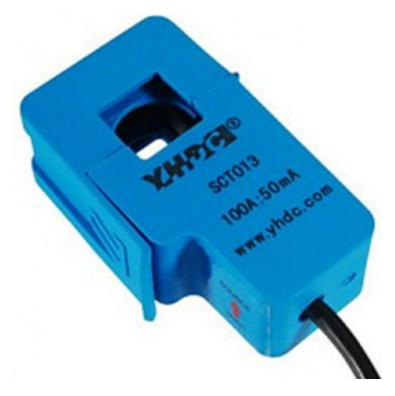

Gambar 1 Sensor Arus SCT013

Sensor arus yang digunakan pada penelitian ini yaitu SCT013-100 yang maksimal mampu mendeteksi arus listrik AC 100 Ampere. Dengan menggunakan SCT013 sebagai sensor arus, tidak perlu dihubungkan secara seri dengan beban namun cukup dengan menggelangkan saja dengan kawat fasa atau netral. Skema rangkaian sensor arus SCT013 diperlihatkan pada Gambar 2. 


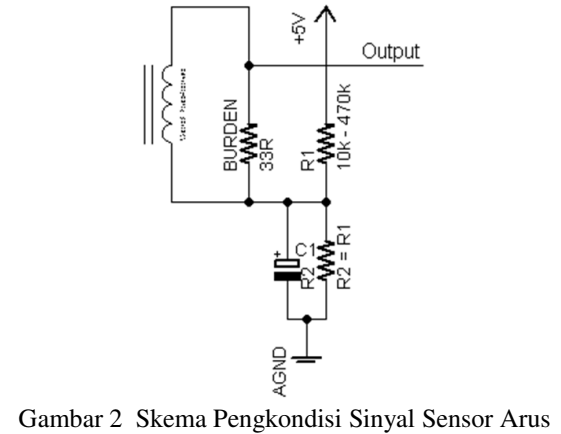

\section{E. Sensor Tegangan}

Sensor tegangan digunakan untuk mengambil data besaran tegangan terhadap ujung terminal yang terhubung dengan beban. Pada aplikasinya sensor tegangan yang digunakan adalah suatu transformator step down 1 Ampere yang akan menurunkan tegangan AC berkisar 220 Volt menjadi tegangan AC 12 Volt yang selanjutnya melalui rangkaian pengkondisi sinyal sehingga rentang tegangan yang dihasilkan dapat diolah oleh mikrokontroler melalui masukan analog to digital converter (ADC).[9] Keluaran dari sensor tegangan ini berupa tegangan berbentuk gelombang sinusoidal. Kalibrasi tegangan dilakukan dengan menempatkan dua buah resistor yang dihubungkan secara seri supaya mendapatkan tegangan yang sesuai dengan referensi ADC mikrokontroler yang digunakan. Bentuk fisik sensor tegangan yang digunakan dan skema rangkaian pengkondisi sinyal ditunjukkan seperti pada Gambar 3 dan Gambar 4.
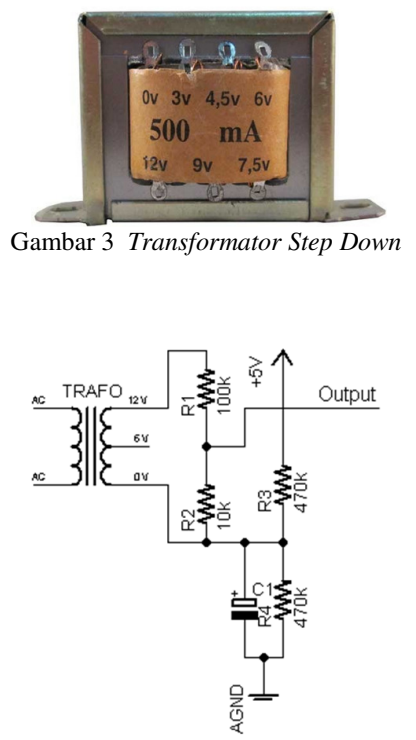

Gambar 4 Skema Pengkondisi Sinyal Sensor Tegangan

\section{F. Pengenalan Android}

Android merupakan sebuah sistem operasi open source yang diperuntukan untuk perangkat bergerak (mobile device). Dikembangkan oleh Open Handset Alliance yang terdiri dari pengembang software, hardware dan provider seperti Google, HTC, Intel, Motorola, Qualcomm, T-Mobile, dan NVIDIA yang bertujuan membuat sebuah standar terbuka untuk perangkat bergerak (mobile device). Pada Juli 2005 Android telah diakuisisi oleh Google dan pada 5 November 2007 barulah secara resmi Android dirilis oleh Google. Dalam pengembangan aplikasi android menyediakan Android SDK (Software Development Kit) yang menyediakan tools dan API (Application Programming Interface) untuk para pengembang aplikasi dengan flatform Android. [10]

\section{Metode Penelitian}

Penelitian ini dilakukan sesuai dengan tahapan-tahapan sesuai dengan flow chart seperti yang ditunjukkan pada Gambar 5. Sebelum pengujian sistem secara keseluruhan dilakukan setelah hardware dan software diwujudkan, diawali dengan pengujian setiap bagian untuk memastikan keberhasilan dan fungsinya sesuai dengan tujuan penelitian.

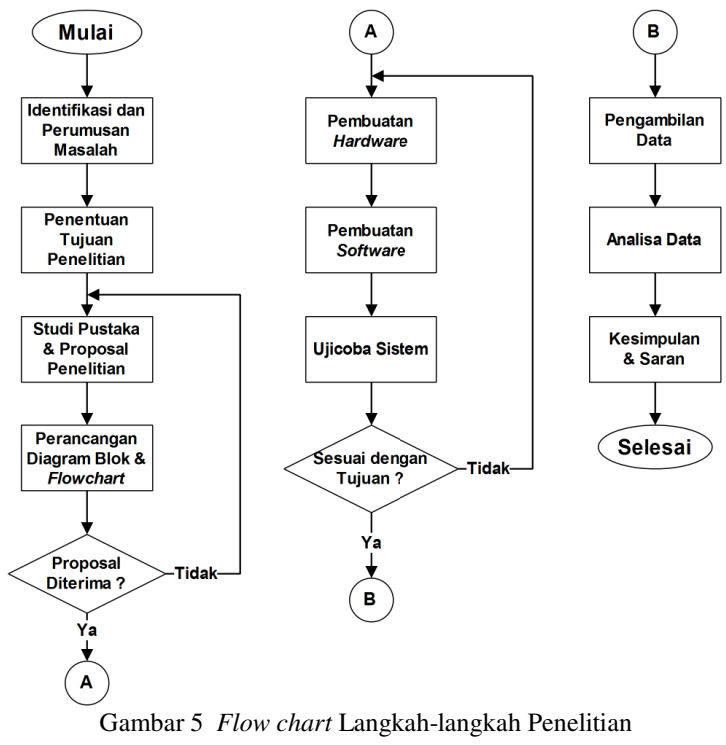

\section{A. Perancangan Perangkat Keras}

Perancangan perangkat keras bertujuan untuk mendapatkan skema atau gambar rangkaian / perangkat keras dari alat yang akan dibuat. Perancangan perangkat keras dimulai dengan pembuatan diagram blok yang berisi blokblok penyusun alat serta hubungan fungsional antar blok. Adapun blok diagram dari alat/perangkat keras yang akan dirancang seperti diperlihatkan pada Gambar 6.

Arus dan tegangan listrik AC akan dideteksi oleh masingmasing sensor yang digunakan pada sub bagian wireless node sensor. Data ADC dari kedua besaran tersebut akan diolah oleh mikrokontroler ATmega328P sehingga menghasilkan parameter-parameter listrik AC. Data tersebut selain ditampilkan pada layar LCD dan disimpan pada SD-Card sebagai data logger, juga akan dikirimkan ke server WSN melalui jaringan Wi-Fi dengan perantara modul ESP8266. Server WSN dapat diakses melalui jaringan LAN melalui web browser dengan alamat IP 192.168.0.123 maupun melalui jaringan internet meggunakan aplikasi Android dengan memanfaatkan server [11]. 


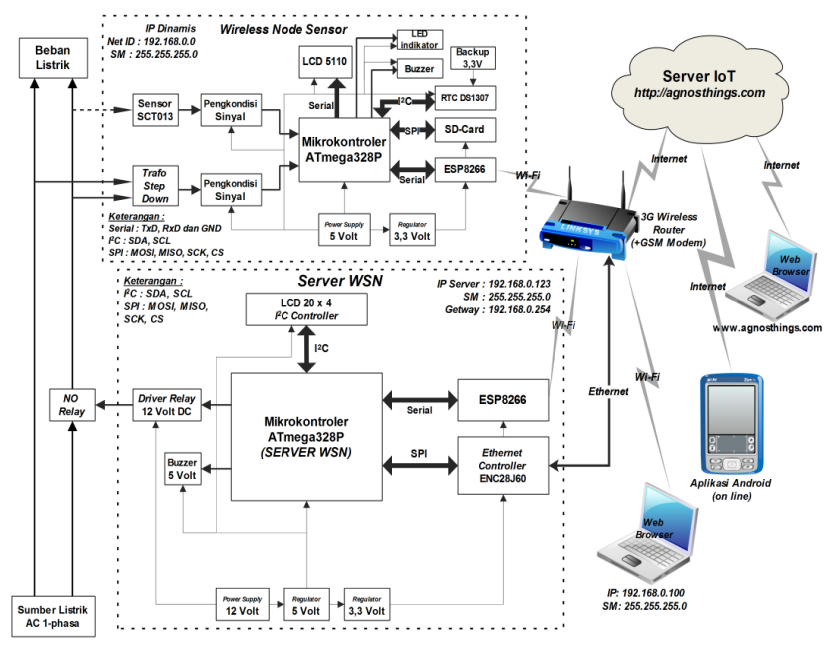

Gambar 6 Diagram Blok Rancangan Sistem

\section{B. Perancangan Perangkat Lunak}

Dalam merancang sistem berbasis mikrokontroler, selain membuat rancangan skema rangkaian secara benar diperlukan juga membuat perangkat lunak yang selanjutnya program tersebut ditanamkan pada memori dari mikrokontroler yang digunakan. Sebelum membuat program dengan menggunakan bahasa C pada IDE Arduino, sangat dibutuhkan terlebih dahulu merancang diagram alir (flow chart) sistem secara keseluruhan. Dari rancangan flow chart tersebut, kemudian diterjemahkan ke dalam bahasa program yang digunakan. Flow chart sistem dari penelitian ini dapat dilihat pada Gambar 7 yang menjelaskan langkah-langkah proses yang dilakukan oleh mikrokontroler ATmega328P pada masingmasing sub sistem yang dirancang yaitu bagian wireless node sensor dan server.

Pada bagian wireless node sensor, mikrokontroler ATmega32P berfungsi mengolah data dari sensor tegangan dan sensor arus menjadi parameter-parameter listrik AC seperti tegangan efektif, arus efektif, daya nyata, daya semu, faktor daya dan jumlah pemakaian energi listrik. Selanjutnya data parameter listrik tersebut selain ditampilkan pada layar LCD dan disimpan pada $S D$-Card, juga akan ditransmisikan ke server melalui jaringan $\mathrm{Wi}-\mathrm{Fi}$ dengan perantara modul ESP8266. Data yang diterima pada bagian server yang terhubung secara wireless dengan node sensor, dapat diakses melalui LAN web browser dan aplikasi Android dengan perantara server [11] secara berperiode.
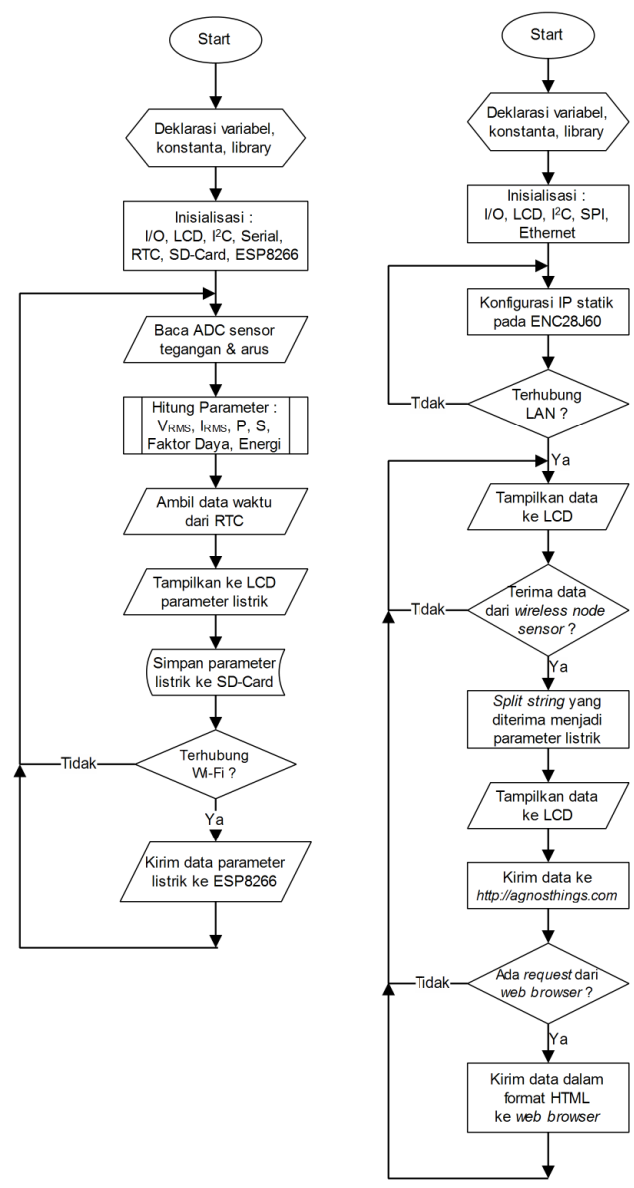

Gambar 7 Flow chart Node Sensor dan Server

\section{HASIL DAN PEMBAHASAN}

Pengujian sistem secara keseluruhan dilakukan setelah masing-masing sub sistem berfungsi dengan baik sesuai dengan yang diharapkan pada saat perancangan. Parameterparameter listrik 1 fasa yang akan dimonitoring yaitu tegangan efektif $\left(\mathrm{V}_{\mathrm{RMS}}\right)$, arus efektif $\left(\mathrm{I}_{\mathrm{RMS}}\right)$, daya aktif $(\mathrm{P})$, daya semu (S), faktor daya (Cos Phi) dan jumlah daya listrik (kWh) yang digunakan pada suatu rentang waktu tertentu. Pengukuran parameter listrik AC tersebut ditunjukkan pada Gambar 8. Semua parameter tersebut akan dilakukan monitoring melalui web browser pada jaringan local area network (LAN) dan internet, yang akan diteliti tingkat kecocokannya dari beberapa sample data dibandingkan dengan data logger pada wireless node sensor sebagai data sumber. 


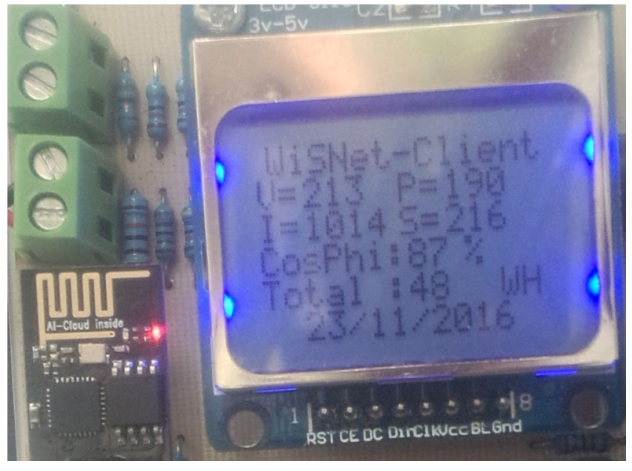

Gambar 8 Wireless Node Sensor

Sensor tegangan dan sensor arus yang digunakan pada modul wireless node sensor akan mendeteksi besar tegangan dan arus listrik bolak balik yang melalui beban. Dari kedua sinyal besaran listrik yang dideteksi ini akan diproses oleh mikrokontroler dengan program yang sudah dirancang yang akan menghasilkan tegangan efektif, arus efektif, daya aktif, daya nyata, faktor daya dan konsumsi daya listrik. Data dari semua parameter listrik tersebut selain ditampilkan pada tampilan LCD juga disimpan pada memori $S D$-card untuk dianalisa lebih lanjut dan setiap 30 detik dikirimkan ke wireless node server melalui jaringan $W i-F i$ yang sebelumnya sudah terhubung dengan node sensor. Sebagai penghubung wireless node sensor dengan jaringan $\mathrm{Wi}-\mathrm{Fi}$, dipergunakan modul ESP8266 yang dikontrol oleh mikrokontroler menggunakan perintah AT-Command. Sebagai penunjuk waktu yang meliputi tanggal dan jam pada saat pengambilan data yang disimpan pada file dengan format CSV (commaseparated value) digunakan IC RTC (real time clock) DS1307. Sebagian file data logger pada SD-Card ditunjukkan pada Tabel 1 .

TABEL I DATA LOGER PADA SD-CARD WIRELESS NODESENSOR

\begin{tabular}{cccccccc}
\hline Tanggal & Jam & $\begin{array}{l}\text { Tegang } \\
\text { an } \\
\text { (Volt) }\end{array}$ & $\begin{array}{l}\text { Arus } \\
\text { (mA) }\end{array}$ & $\begin{array}{l}\text { Daya } \\
\text { Aktif } \\
\text { (Watt) }\end{array}$ & $\begin{array}{l}\text { Daya } \\
\text { Nyata } \\
\text { (VA) }\end{array}$ & $\begin{array}{l}\text { Faktor } \\
\text { Daya } \\
(\%)\end{array}$ & $\begin{array}{l}\text { Energi } \\
\text { (Wh) }\end{array}$ \\
\hline $23 / 11 / 2016$ & $15: 21: 09$ & 213 & 4243 & 898 & 904 & 99 & 6 \\
$23 / 11 / 2016$ & $16: 09: 21$ & 214 & 6528 & 1399 & 1400 & 99 & 172 \\
$23 / 11 / 2016$ & $17: 10: 32$ & 214 & 687 & 126 & 147 & 85 & 373 \\
$23 / 11 / 2016$ & $18: 33: 03$ & 208 & 3939 & 805 & 822 & 97 & 520 \\
$23 / 11 / 2016$ & $19: 21: 12$ & 204 & 5275 & 1070 & 1081 & 99 & 779 \\
$23 / 11 / 2016$ & $20: 30: 58$ & 210 & 5190 & 1082 & 1094 & 98 & 1162 \\
$23 / 1112016$ & $21: 15: 01$ & 211 & 4390 & 898 & 926 & 96 & 1420 \\
$23 / 11 / 2016$ & $22: 05: 31$ & 208 & 3681 & 749 & 769 & 97 & 1689 \\
$23 / 11 / 2016$ & $23: 05: 33$ & 214 & 3471 & 720 & 745 & 96 & 2016 \\
$24 / 11 / 2016$ & $0: 05: 33$ & 213 & 3732 & 775 & 798 & 97 & 2405 \\
$24 / 11 / 2016$ & $1: 05: 36$ & 217 & 3293 & 668 & 715 & 93 & 2819 \\
\hline
\end{tabular}

Masing-masing record yang ditunjukkan pada Tabel 1 terdiri dari delapan field yaitu tanggal, jam, tegangan, arus, daya aktif, daya nyata, faktor daya dan energi listrik. Dari record pertama dan terakhir menunjukkan rentang waktu pengambilan data yang dilakukan kurang lebih selama sembilan jam yaitu dari pukul 15.21 hingga pukul 1.05 dini hari. Dari hasil penelitian tersebut juga dapat dilihat konsumsi energi listrik sebesar 2819 Watt hour atau 2,819 kWh.

Data yang disimpan oleh wireless node sensor ini juga akan dikirim ke server yang terhubung melalui port Ethernet pada wireless router 3G MR-3020 dengan IP address 192.168.0.123/24. Data parameter listrik yang diterima oleh server ini selain dapat diakses melalui web browser jaringan LAN seperti yang ditunjukkan pada Gambar 9, juga akan diupload ke server. Server [11] adalah server di internet yang dapat digunakan secara gratis oleh para pengembang Internet of Things, dimana access point yang terhubung dengan server lokal alat yang dibuat harus terhubung dengan modem yang berisi paket data untuk bisa terhubung ke global internet.

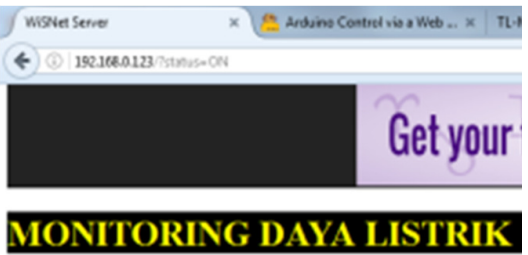

\author{
Tegangan AC (Volt): 217 \\ Arus (miliAmpere) : 3293 \\ Daya Aktif (Watt) : 668 \\ Daya Nyata (VA) : 715 \\ Faktor Daya (96) : 93 \\ Total Daya (WH) : 2819 \\ Status Beban Listrik: ON off \\ Gambar 9 Tampilan pada Web Browser LAN
}

Gambar 9 menunjukkan tampilan monitoring parameter listrik pada web browser LAN yang ditunjukkan dengan alamat IP address server 192.168.0.123. Data parameter listrik yang ditampilan pada web browser ini, merupakan data yang dikirimkan dari wireless node server seperti yang ditunjukkan pada record terakhir di Tabel 1 yang menunjukkan data yang sama dengan data pada wireless node sensor.

Selanjutnya selain melakukan monitoring melalui LAN web browser, pada penelitian ini juga dibuat aplikasi berbasis Android yang terhubung secara langsung dengan server [11]. Aplikasi Android dibangun menggunakan Apache Cordova berbasis HTML yang di-edit menggunakan software IDE Rapid CSS 2016. Hasil monitoring melalui gadget Android yang sudah ter-install aplikasi yang dirancang sebelumnya ditunjukkan pada Gambar 10. Nilai yang ditunjukkan pada aplikasi tersebut akan berubah secara berperiode sesuai dengan update data pada server [11].

Dari tampilan hasil monitoring penggunaan daya listrik sebagai implementasi internet of things berbasis wireless sensor network dapat dicermati bahwa besaran dari masingmasing record adalah identik sehingga dapat disimpulkan sistem secara keseluruhan dapat bekerja dengan baik sesuai dengan rancangan yang diharapkan. Rekapan data hasil monitoring dari data logger node sensor, web browser jaringan LAN, web browser internet dan aplikasi Android dapat diamati pada Tabel 2. 


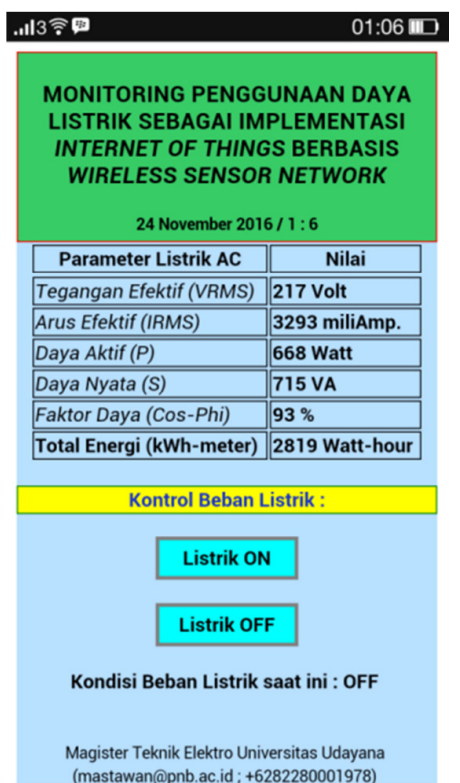

Gambar 10 Monitoring Melalui Gadget Android

TABEL II

REKAPAN HASIL MONITORING PARAMETER LISTRIK

\begin{tabular}{lllllll}
\hline $\begin{array}{l}\text { Device } \\
\text { Monitoring }\end{array}$ & $\begin{array}{l}\text { Tegan } \\
\text { gan } \\
\text { (Volt) }\end{array}$ & $\begin{array}{l}\text { Arus } \\
(\mathrm{mA})\end{array}$ & $\begin{array}{l}\text { Daya } \\
\text { Aktif } \\
\text { (Watt) }\end{array}$ & $\begin{array}{l}\text { Daya } \\
\text { Nyata } \\
\text { (VA) }\end{array}$ & $\begin{array}{l}\text { Faktor } \\
\text { Daya } \\
(\%)\end{array}$ & $\begin{array}{l}\text { Energi } \\
(\text { Wh })\end{array}$ \\
\hline $\begin{array}{l}\text { Data logger node } \\
\text { sensor }\end{array}$ & 217 & 3293 & 668 & 715 & 93 & 2819 \\
& & & & & & \\
$\begin{array}{l}\text { Web browser } \\
\text { LAN }\end{array}$ & 217 & 3293 & 668 & 715 & 93 & 2819 \\
$\begin{array}{l}\text { IP:192.168.0.123 } \\
\text { Browser internet } \\
\text { http://agnosthing }\end{array}$ & 217 & 3293 & 668 & 715 & 93 & 2819 \\
s.com & & & & & & \\
$\begin{array}{l}\text { Aplikasi } \\
\text { "WiSNet" gadget } \\
\text { Android }\end{array}$ & 217 & 3293 & 668 & 715 & 93 & 2819 \\
\hline
\end{tabular}

\section{KESIMPULAN}

Berdasarkan analisa data yang diperoleh dari hasil penelitian yang dilakukan, dapat ditarik simpulan sebagai berikut:

1. Modul ESP8266 terbukti secara handal mampu mengirimkan paket data yang terdiri dari parameter listrik AC secara bersamaan ke suatu server melalui jaringan $\mathrm{Wi}$ $F i$ yang tersedia.

2. Aplikasi pada perangkat mobile Android yang dibuat dapat memonitor parameter listrik AC seperti tegangan efektif $\left(\mathrm{V}_{\mathrm{RMS}}\right)$, arus efektif $\left(\mathrm{I}_{\mathrm{RMS}}\right)$, daya aktif $(\mathrm{P})$, daya semu $(\mathrm{S})$, faktor daya $(\operatorname{Cos} P h i)$ dan jumlah daya listrik $(\mathrm{kWh})$ serta mampu mengontrol beban listrik melalui internet.

\section{REFERENSI}

[1] Sentanu M, Ida Bagus Putra, Rukmi Sari Hartati dan I Nyoman Satya Kumara, "Pengelolaan Energi Listrik pada Gedung Fakultas Kedokteran Universitas Udayana Kampus Sudirman Denpasar," Jurnal Teknik Elektro Unud, Vol. 11 No.2, pp. 25-32, Juli - Desember 2012.

[2] Junaidi, Apri, "Internet of Things, Sejarah, Teknologi dan Penerapannya : review," Jurnal Ilmiah Teknologi Informasi Terapan, Volume I, Nomor 3, pp. 62-66, Agustus 2015

[3] Pratama, I Putu Agus Eka dan Sinung Suakanto, Wireless Sensor Network, Bandung: Informatika Bandung, 2015.

[4] Firdaus, Wireless Sensor Network : Teori dan Aplikasinya, Yogyakarta : Graha Ilmu, 2014.

[5] Firdaus dan Toha Ardi Nugraha, The Next Generation of ICT Network : NGN, FTTH, M2M, WSN, IoT, Yogyakarta : Teknosain, 2016.

[6] Direktorat Jenderal Aplikasi Informatika. (2015) "Dari Internet of Things Menuju Smart City dan Smart Peope." [Online]. Available: http://aptika.kominfo.go.id/index.php/artikel/73-dari-internet-of-thingmenuju-smart-city-dan-smart-people

[7] Fayruzrahma. (2016) "Arsitektur Jaringan Internet of Things." [Online]. Available: https://fayruzrahma. wordpress.com/ 2016/03/23/arsitektur-jaringan-internet-of-things/

[8] "ESP8266 802.11bgn Smart Device," Espressif Systems. Datasheet.

[9] Sakti, Setyawan P, "Rancang Bangun Sistem Pembatas Arus Daya Kecil Tegangan 220VAC Berbasis Mikrokontroler," Teknologi Elektro, Vol. 15, No.1,pp. 103-110, Juni 2016

[10] Djuni H, I G. A. K. Diafari, I G A P Raka Agung, N. Pramaita dan Made Sugiri, "Pembuatan Prototype Sistem Pengendali Lampu Rumah dengan Perangkat Mobile Android,' Jurnal Teknologi Elektro, Vol. 14, No.2, pp. 22-26, Desember 2015.

[11] (2016) Website flatform Internet of Things. [Online]. Available: http://agnosthings.com

IGP Mastawan Eka Putra: Monitoring Penggunaan Daya Listrik.... 